\title{
UMA ABORDAGEM DIDÁTICO-PEDAGÓGICA NA PREVENÇÃO DAS INFECÇÕES SEXUALMENTE TRANSMISSÍVEIS: RELATO DE EXPERIÊNCIA
}

\author{
Marysther Françoso Teixeira Costa \\ Mestrado Profissional em Ensino de Biologia pela Universidade Federal de Juiz de Fora (UFJF) \\ marysthercosta@yahoo.com.br
}

Rodrigo Hohl Pós-doutorado em Ciência do Esporte pela Universidade Estadual de Campinas (UNICAMP) Pós-doutorado em Psicologia pela Universidade Federal de Juiz de Fora (UFJF) Professor adjunto do Departamento de Fisiologia do Instituto de Ciências Biológicas da (UFJF) hohlrodrigo@gmail.com

Carlos Alberto Mourão Júnior Pós-Doutorado no Instituto de Matemática Pura e Aplicada (IMPA) Professor Associado da Universidade Federal de Juiz de Fora (UFJF) camouraojr@gmail.com

\section{RESUMO}

Muitos adolescentes são incrédulos a respeito de sua própria vulnerabilidade no que tange às infecções sexualmente transmissíveis (ISTs). Este trabalho teve como objetivo estruturar uma unidade didática para orientar alunos no último ano do ensino médio na tarefa de elaboração de materiais ou atividades sobre prevenção e consequências das ISTs. As propostas didáticas elaboradas pelos estudantes foram embasadas no contexto trabalhado em aulas e nas pesquisas sobre o tema na intenção de que, como protagonistas na construção do conhecimento, eles alcançassem uma aprendizagem significativa através de uma metodologia ativa de ensino. Ao longo desse processo, foi perceptível a ludicidade nas propostas, elaboradas com muita criatividade e autenticidade, o que reforça a ideia de que há de se considerar o indivíduo em todos os seus aspectos, na perspectiva de que o entretenimento, as emoções e as atitudes devem caminhar lado a lado com o conhecimento.

Palavras-chave: Adolescentes. Aprendizagem significativa. Metodologia ativa.

\section{A DIDACTIC-PEDAGOGICAL APPROACH IN PREVENTION OF SEXUALLY TRANSMITTED INFECTIONS: EXPERIENCE REPORT}

\begin{abstract}
Many adolescents are incredulous about their own vulnerability when it comes to sexually transmitted infections (STIs). This work aimed to plan a didactic unit to guide students in the preparation of materials or activities about prevention and consequences of STIs. The didactic proposals developed by the students were based on the context worked in classes
\end{abstract}


and on the autonomous research about STIs. As protagonists in the development of their own of knowledge, students would achieve a meaningful learning about STIs through the active learning proposal detailed here. Throughout this process, the playfulness in the proposals was noticeable, elaborated with creativity and authenticity, which reinforces the idea that the individual must be considered in all its aspects, in the perspective that entertainment, emotions and attitudes must go hand in hand with knowledge.

Keywords: Adolescents. Meaningful learning. Active methodology. 


\section{INTRODUÇÃO}

O ensino de biologia tem objetivos como desenvolver a consciência ambiental, investigar as relações existentes entre seres vivos e não vivos e, sobretudo, fornecer argumentos científicos para a compreensão do universo e a vida (BORBA, 2013). Essa visão abrangente sobre o ensino de biologia encontra respaldo nos Parâmetros Curriculares Nacionais (PCN), que orienta:

\footnotetext{
A formação do aluno deve ter como alvo principal a aquisição de conhecimentos básicos, a preparação científica e a capacidade de utilizar as diferentes tecnologias relativas às áreas de atuação.

Propõe-se, no nível do Ensino Médio, a formação geral, em oposição à formação específica; o desenvolvimento de capacidades de pesquisar, buscar informações, analisá-las e selecioná-las; a capacidade de aprender, criar, formular, ao invés do simples exercício de memorização. (BRASIL, 2000a, p. 6).
}

Em tese, o PCN encoraja o professor do ensino médio a adotar metodologias ativas que promovam a autonomia, a instrução autorregulada e a problematização como estratégias de ensino (MITRE et al., 2008). Entretanto, uma triste realidade assombra o ensino de atualmente, no qual, predominantemente, são realizadas aulas expositivas, conhecidas como tradicionais, nas quais o professor se considera o único detentor do conhecimento e, quando há participação de alguns estudantes, estes muitas vezes não encontram significados nas aulas, sentindo-se desmotivados e apáticos. Faz-se necessário, então, ir além, despertar a curiosidade do aluno, o seu interesse pelo conteúdo com estratégias que minimizem suas dificuldades na proposta a ser trabalhada e também lançar mão de diversificadas formas de avaliações, contemplando o ser humano de forma holística nas estratégias e metodologias visando a uma aprendizagem significativa.

Segundo Moreira e Masini (2012), aprendizagem significativa é aquela em que ideias fazem interações não arbitrárias com o que o aprendiz já sabe, com algum conhecimento previamente relevante em sua estrutura cognitiva. Diz respeito ao aluno trazer consigo, em teor de bagagem, o dito conhecimento prévio. Pois é dessa forma que ele é capaz de estabelecer conexões com o novo, com as descobertas posteriores. A esse parâmetro anterior ao novo conhecimento, David Ausubel (2003) chama de subsunçor, ou ideias âncoras. De maneira geral, subsunçor é um conhecimento específico que já existe na estrutura cognitiva e serve de base para o novo aprendizado. 
No que tange, por exemplo, ao conteúdo sobre sexualidade, os alunos trazem consigo uma familiaridade intrínseca, construída informalmente ${ }^{1}$ ao longo da vida, em que as descobertas vêm desde a primeira infância, intensificam-se na puberdade e têm características de alta relevância que seguem pela vida. Adolescentes, geralmente, tem um despertar aguçado por assuntos a este respeito, pois estão envolvidos em mudanças biológicas, psicológicas e sociais de ordem profunda que influenciam diretamente na construção de sua identidade. É um período de destemor e de descobertas e incertezas com uma constante busca por desafios e experimentações do novo. Toda a evolução que acontece nessa fase caracteriza um amadurecimento físico e emocional. É nela que os jovens descobrem seu papel social. Segundo a Organização Mundial da Saúde (OMS) (NÚMERO, 2018), a adolescência corresponde à fase de transição de um indivíduo da infância para a maturidade e compreende o intervalo de tempo que vai de 10 a 19 anos de vida.

Ainda que inseridos numa sociedade dita contemporânea, os adolescentes se veem presos a um paradigma de que a livre expressão da sexualidade é interpretada como uma transgressão. Dessa forma, e muitas das vezes, evitam procurar conselhos e informações seguras relacionados a esse aspecto (BRÁS, 2008). Paralelamente, por ser a adolescência um período caracterizado por experimentações de um turbilhão de novas sensações e sentimentos, a falta de percepção da própria vulnerabilidade justifica o alto número de jovens com infeç̧ões sexualmente transmissíveis (IST) que configuram um conjunto de distintas infecções passíveis de contágio através do ato sexual (CIRIACO et al., 2019).

Uma estimativa do Ministério da Saúde (BRASIL, 2018) relata que um em cada vinte adolescentes, na faixa etária entre 15 a 24 anos $^{2}$, adquire uma IST (não incluindo a AIDS e as hepatites) a cada ano. Dentre as IST, o Vírus da Imunodeficiência Humana (HIV), causador da Síndrome da Imunodeficiência Adquirida (AIDS) é um constante desafio à saúde pública mundial. Desde a década de 1980, quando se deu início à epidemia da Aids, até junho de 2017, foram identificados 882.810 casos da doença no Brasil, com uma média anual de 40 mil novos casos nos últimos cinco anos (BRASIL, 2017). A estatística mostra que, dos casos de HIV/AIDS no mundo, um terço está concentrado na população jovem entre 10 e 24 anos

\footnotetext{
1 Termo atribuído à educação desenvolvida fora dos estabelecimentos de ensino ou que ocorre sem planejamento. Uma característica marcante dessa educação é a aparente naturalidade do processo, ocultando valores, signos e até preconceitos. No entanto, os meios educativos informais exercem grande influência na formação dos indivíduos. (MENEZES, 2001).

${ }^{2}$ Neste caso, utilizou-se a definição da Organização das Nações Unidas (ONU) que considera a adolescência um período de juventude (youth) entre os 15 e 24 anos. (EISENSTEIN, 2005).
} 
(OLIVEIRA et al., 2009). E, a cada ano, calculam-se aproximadamente 357 milhões de novas infecções, como clamídia, gonorreia, sífilis e tricomoníase (BRASIL, 2018). Ainda segundo dados da OMS (NÚMERO, 2018), atualmente grande parte dos adolescentes inicia a vida sexual cada vez mais cedo, entre os 12 e os 17 anos. Muitas das vezes as infecções sexualmente transmissíveis são de difícil detecção, pois podem passar longos períodos ou até a vida toda de forma assintomática, ainda que o indivíduo seja um potencial transmissor das mesmas.

Ao considerar minha experiência como docente de um público jovem, observo frequentes casos de gravidez precoce ou mesmo indesejada, e dados alarmantes (anteriormente citados) da Organização Mundial da Saúde evidenciam o aumento das infecções sexualmente transmissíveis pautado na descrença de boa parcela dos jovens sobre a própria vulnerabilidade. Para agravar a situação, o consumo de álcool entre adolescentes é muito elevado e, sob efeito desinibidor do álcool, qualquer estratégia de prevenção - como o uso de preservativos - cai no esquecimento. Em face desse preocupante cenário, que traz consigo sérias implicações sociais e sanitárias, este trabalho buscou estratégias que levem, efetivamente, ao interesse dos discentes no que tange ao conteúdo das IST.

As políticas públicas de saúde defendem que a escola é um espaço fértil para o compartilhamento de promoção, prevenção e educação para a saúde. Ao serem ministradas de formas responsáveis e interessantes, as informações constroem sujeitos sociais críticos e disseminadores de conhecimentos (GOMES, 2002).

A unidade didática, produto exibido neste trabalho, teve como referência a teoria da aprendizagem significativa (AUSUBEL, 2003), uma vez que se destina a inserir o tema sobre infecções sexualmente transmissíveis com uma proposta didática que parte do conhecimento prévio dos alunos, de tal forma que possam desenvolver habilidades para compreenderem o universo ao seu redor e interferirem nele considerando as próprias experiências individuais. Possui o objetivo de ser uma proposta facilitadora da assimilação do conteúdo, principalmente no que tange às IST, na intenção de uma leitura e interpretação mais consciente das informações veiculadas e na possibilidade de se posicionar criticamente diante delas. 


\title{
2 DESENVOLVIMENTO
}

Este trabalho foi desenvolvido na Escola Estadual Raul Soares, situada no município de Ubá, Minas Gerais. O público-alvo foi uma das turmas do terceiro ano do ensino médio regular diurno, com 41 alunos, variando a faixa etária entre 17 e 19 anos. Tal escolha respaldou-se no fato de os sujeitos serem jovens adultos ${ }^{3}$, com esperada maturidade para a abordagem do tema. Como critério de inclusão, levou-se em consideração os alunos matriculados na referida turma no ano letivo de 2020. Como critério de não inclusão, foram desconsiderados aqueles que se mantiveram faltosos até a finalização do projeto, ou se negaram a participar.

Seguindo a grade curricular do estado de Minas Gerais, a disciplina de Biologia é ministrada em duas aulas semanais, cada aula com 50 minutos e, na maioria das vezes, geminadas. Considerou-se o uso de 3 aulas, ou seja, 150 minutos, para ordenar as atividades didáticas numa sequência planejada.

A sequência didática é uma ordenação articulada de atividades de ensino/aprendizagem. Os tipos e a ordenação das atividades em sequência formam uma unidade didática com características próprias e diversas (ZABALA, 1998). A unidade didática deste trabalho foi composta em três etapas:

\section{1a etapa - Organizador prévio}

Sobre os organizadores prévios, Moreira (2012) esclarece:

\begin{abstract}
Organizador prévio é um recurso instrucional apresentado em um nível mais alto de abstração, generalidade e inclusividade em relação ao material de aprendizagem (...). Pode ser um enunciado, uma pergunta, um filme, uma leitura introdutória, uma simulação. Pode ser também uma aula que precede um conjunto de outras. As possibilidades são muitas, mas a condição é que preceda a apresentação do material de aprendizagem e que seja mais abrangente, mais geral e inclusivo do que este. (Moreira, 2012, p. 30).
\end{abstract}

A principal função de um organizador prévio é servir de ponte entre o que o aprendiz já sabe e o que ele ainda precisa saber. Quando a nova informação é

\footnotetext{
${ }^{3}$ Conforme Art. 2 da lei federal $n^{\circ} 8.069$, considera-se criança a pessoa até doze anos de idade incompletos, e adolescente aquela entre doze e dezoito anos de idade. Em respeito à legislação brasileira, utilizamos a designação jovem adulto para incluir os estudantes acima dos 18 anos.
} 
completamente não-familiar, um organizador prévio expositivo pode ser usado para promover subsunçores aproximados que possam servir como âncora inicial. Caso o aprendiz já possua subsunçores familiares à nova informação, um organizador prévio comparativo auxilia a integração da nova informação com o conhecimento preexistente pela discriminalidade entre ideias novas e prévias.

Esta primeira etapa foi composta por uma sequência didática com três atividades: (1) uma aula dialogada, (2) apresentação de vídeos sobre ISTs, (3) pesquisa bibliográfica. O objetivo da primeira etapa foi facilitar a integração do conhecimento prévio do aluno com as novas informações. Como atividade didática, o organizador prévio também seria um recurso instrucional com potencial de gerar o interesse e o engajamento produtivo ao provocar no estudante a predisposição para aprender significativamente (HOHL et al., 2019). Uma condição fundamental para a aprendizagem significativa diz respeito à predisposição do sujeito a acionar os próprios subsunçores, denotando o desejo de aprender significativamente (AUSUBEL, 2003).

\section{2a etapa - Tarefa de aprendizagem}

Como quarta atividade, foi solicitada a produção de um material didático e a elaboração de uma apresentação que estabelecesse relações entre os subsunçores, as informações dos vídeos exibidos e os dados encontrados nas pesquisas.

A quarta atividade é uma tarefa de aprendizagem para o exercício dos princípios de assimilação da informação na estrutura cognitiva, tais quais, aprendizagem distribuída, intercalagem de informações, relembrança, elaboração, utilização de exemplos concretos explicativos e dupla codificação (i.e., relacionar texto e imagem). (WEINSTEIN; MADAN; SUMERACKI, 2018).

\section{3a etapa - Expressão e comunicação}

Apresentação dos materiais didáticos elaborados pelos próprios alunos. 


\section{Aulas 1 e 2 - Introdução e Desenvolvimento do tema}

\section{Objetivos dessas aulas:}

- $\quad$ Reconhecer a importância da prevenção das IST

- $\quad$ Apontar os principais modos de contaminação

- Identificar as principais IST

\section{Sequência didática das aulas 1 e 2}

1a etapa, atividade 1 (30 minutos): Atividade destinada a uma conversa informal na intenção de identificar conhecimentos prévios dos alunos. Optou-se por questionar se algum aluno tinha conhecimento familiar ou de amigos sobre gravidez na adolescência, riscos de IST no ato sexual desprotegido e outras formas de contágio.

1a etapa, atividade 2 (40 minutos): Apresentação de vídeos relacionados com a conversa já iniciada. Vídeos, esses, selecionados previamente e de tal forma que preferencialmente não ultrapassassem 20 minutos de exibição abordando sintomas de algumas das principais infecções sexualmente transmissíveis, sendo elas: herpes genital, sífilis, gonorreia, clamídia, HPV, hepatite B (VHB), hepatite D (VHD), cancro mole, HIV, Mycoplasma genitalium, Doença inflamatória pélvica (DIP), donovanose, linfogranuloma venéreo e tricomoníase. No caso dessa atividade, foram exibidos vídeos de cinco principais IST (HIV/AIDS, HPV, sífilis, gonorreia e herpes genital) e os alunos foram orientados antes do início de cada vídeo a fazerem anotações no caderno das informações que considerassem relevantes.

1a etapa, atividade 3 (15 minutos): Pesquisa em artigos com estimativas atuais mundiais e brasileiras das principais IST, envolvendo diferentes faixas etárias, ressaltada a importância de que a pesquisa fosse feita preferencialmente dentro de plataformas acadêmicas.

2a etapa, atividade 4 (15 minutos): A turma foi dividida em quatro grandes grupos com média de 9 pessoas em cada. Para facilitar e viabilizar a produção de um material didático coerente, apresentou-se sugestões acerca de quais materiais didáticos poderiam ser 
produzidos (jogos, cartilhas etc.). Os discentes se organizaram em grupos à distância para que a construção do trabalho acontecesse com eficiência, utilizando-se de mídias sociais, principalmente por aplicativo WhatsApp.

\section{Aula 3 - Apresentação dos trabalhos}

\section{Objetivos desta aula:}

- $\quad$ Relembrar as principais IST

- Identificar modo de transmissão das principais IST

- $\quad$ Reconhecer agentes patogênicos de cada uma das principais IST

- Identificar principais sintomas das doenças

3a etapa, atividade 5 (50 minutos): Momento destinado à apresentação das propostas e, se possível, a aplicação das mesmas.

\section{RESULTADOS}

O desafio lançado aos alunos culminou em alguns roteiros de propostas de trabalhos que serão apresentadas a seguir.

\section{Grupo 1 - Peça Teatral:}

O grupo que decidiu pela peça teatral escreveu o roteiro (Figura 1) e construiu, inclusive, o cenário e os figurinos dos participantes. O espetáculo contaria com música e jogos de luzes. A peça seria intitulada "Prevenir é um ato de amor!" 
Figura 1 - História da Peça Teatral.

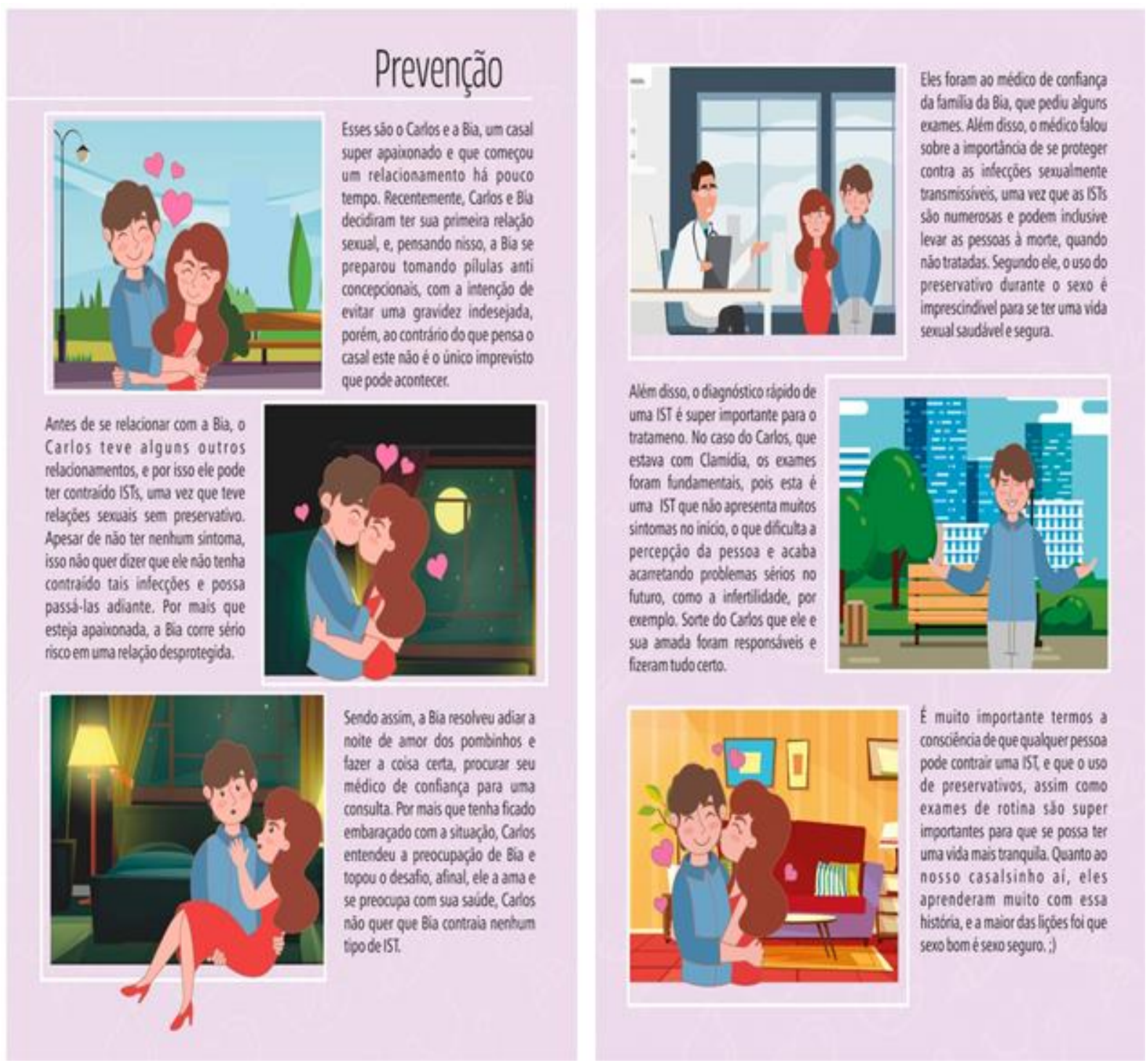

Fonte: Elaborado pelos alunos e Autora (2021).

\section{Grupo 2 - Palestra com agentes da Saúde:}

O grupo que propôs a ideia de palestras com agentes de saúde angariou material (Figuras 2, 3, 4 e 5) em postos de saúde como folhetos informativos e preservativos. Começou também a construir um folder personalizado como forma de chamada do público geral da escola para assistir à apresentação que teria data e hora marcada para acontecer. 
Figura 2 - Preservativos lúdico e para distribuição.

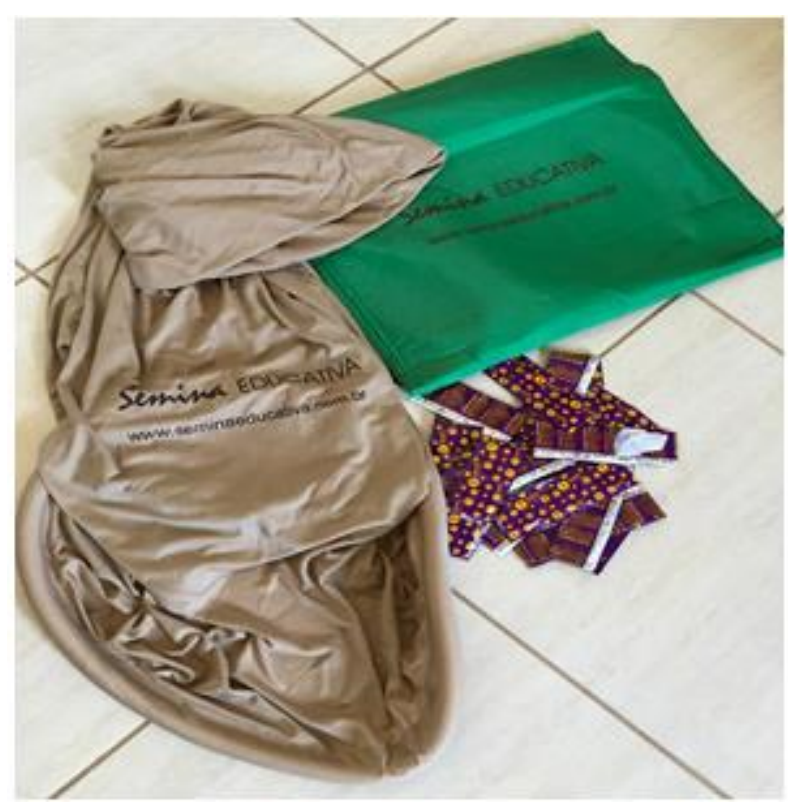

Fonte: Fornecido pelos alunos e autora (2021).

Figura 3 - Folhetos informativos sobre IST.

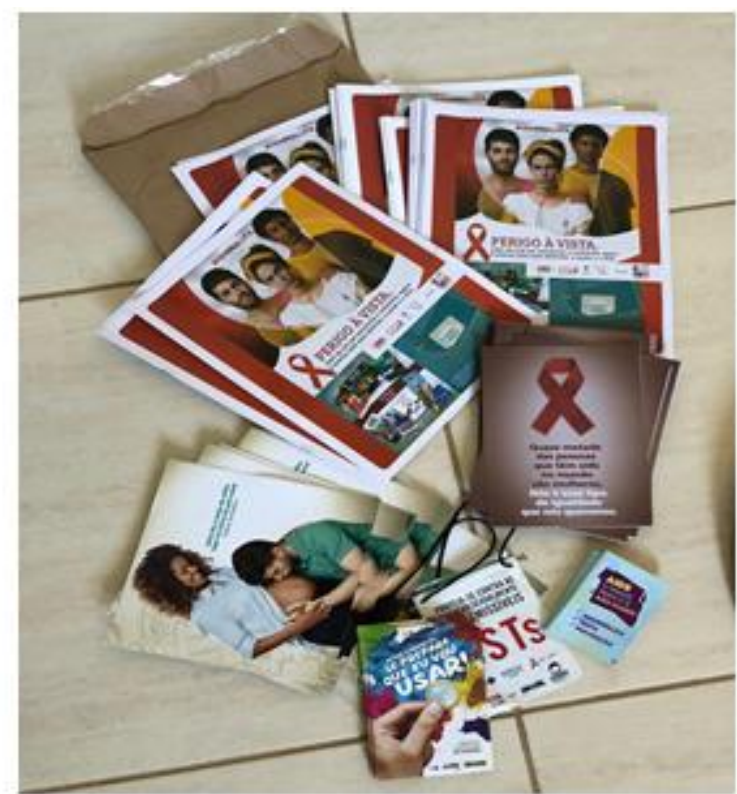

Fonte: Fornecido pelos alunos e autora (2021). 
Figura 4 - Camisa símbolo prevenção.

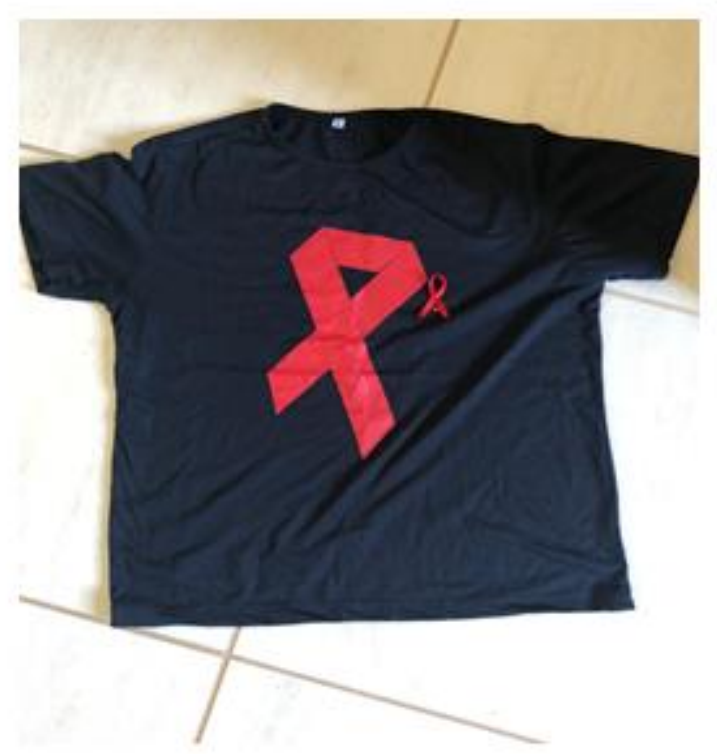

Fonte: Fornecido pelos alunos e autora (2021).

Figura 5 - Materiais palestra.

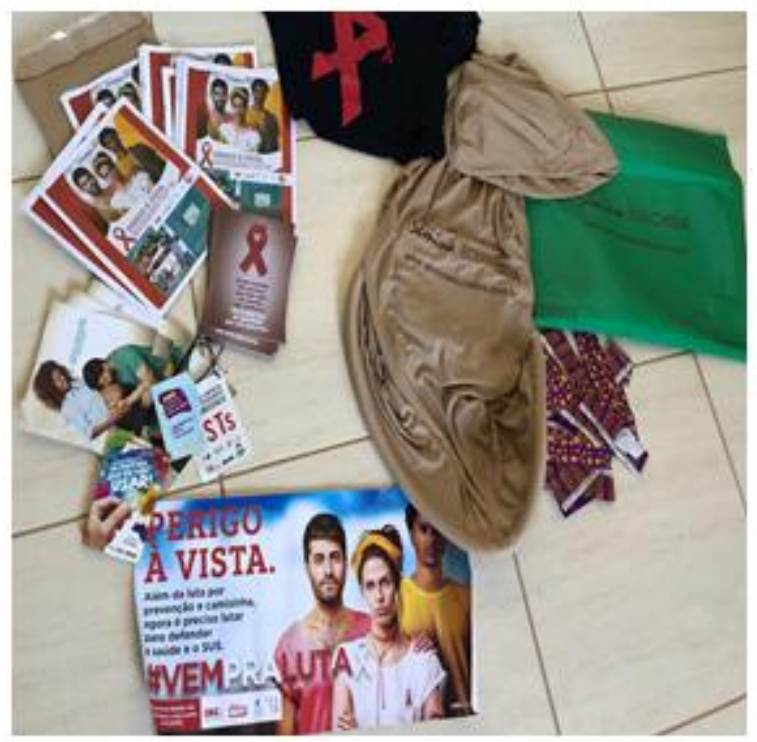

Fonte: Fornecido pelos alunos e autora (2021).

\section{Grupo 3 - Jogo Cara a Cara:}

Os alunos propuseram uma nova versão do jogo Cara a Cara, intitulando-o como "Cara a Cara com uma IST", no qual cada pessoa que representasse seu grupo (o líder) teria o nome de uma IST preso num arco em volta da cabeça (Figura 6). Diante de uma sequência 
de perguntas disparadas por esse mesmo aluno e com respostas dos demais colegas, ele teria de descobrir qual IST era a indicada em seu arco. A partida começa quando o jogador (que pode representar uma equipe composta por 3 ou 4 alunos, para dinamizar o jogo) lança um dado e percorre no tabuleiro (Figura 7) o número do lançamento do dado. Quando atingir uma determinada casa onde tem a correspondência de uma carta (no tabuleiro cada casa possui um número correspondente a uma carta), essa por sua vez, é colocada no arco que estará em sua cabeça. Isso acontecerá até que todas as equipes estejam no jogo. Quando a equipe identificar corretamente a IST correspondente, lança novamente o dado, rumo a uma nova descoberta. Ganha a equipe que identificar corretamente mais IST. Em resumo, o aluno deveria descobrir qual carta indicativa de uma IST estará presa em seu arco a partir de perguntas que ele próprio formulará aos demais colegas, sem que estes entreguem a resposta prontamente. Portanto, é fundamental um estudo prévio do conteúdo.

Exemplos de perguntas a serem feitas:

“Essa IST é causada por um vírus?!

"Essa IST é tratada com antibiótico?"

"Cite 3 sintomas dessa IST"

A fim de englobar toda a turma, deveriam ser construídas 3 ou quatro equipes para esse jogo.

Figura 6 - Jogo Cara a Cara.

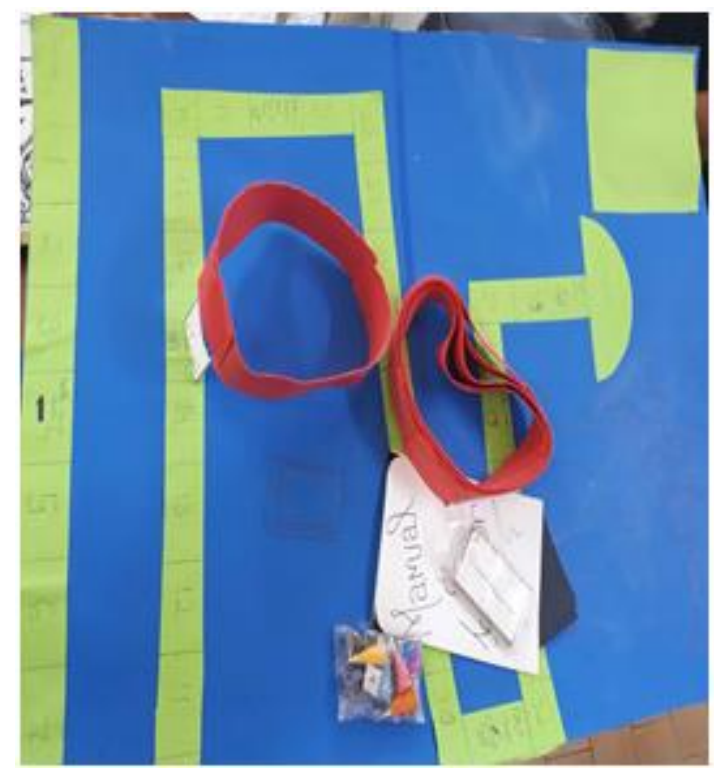

Fonte: Fornecido pelos alunos e autora (2021). 
Figura 7 - Arco jogo cara a cara.

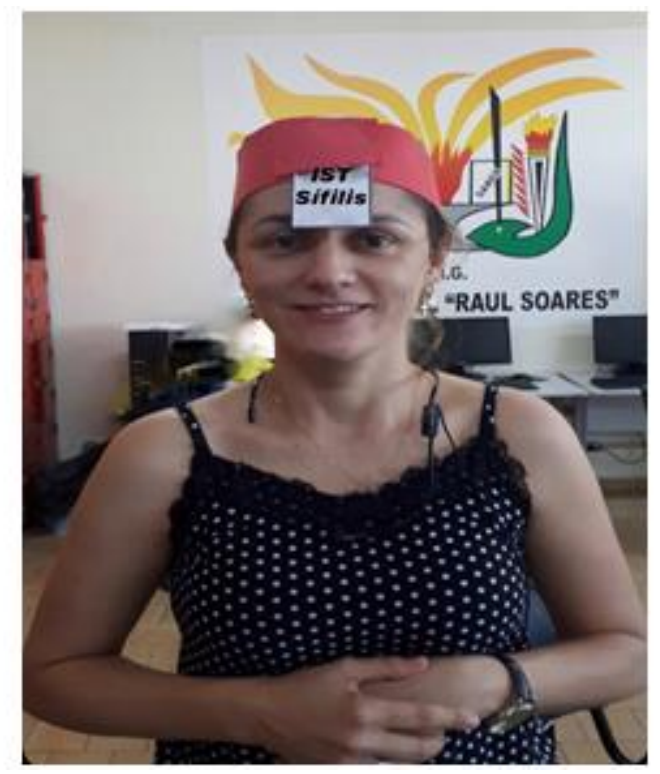

Fonte: Fornecido pelos alunos e autora (2021).

\section{Grupo 4 - Jogo de Tabuleiro:}

Para a aplicação do jogo, a turma, dividida em quatro grupos, comporia equipes rivais. Esse jogo é constituído de: um tabuleiro (Figura 8) com cinquenta casas enumeradas em ordem crescente, quarenta e quatro cartas (Figura 9), um cronômetro, que pode inclusive, ser o de um celular, um manual de utilização do jogo, um dado e pinos (Figura 10), estes, por sua vez, distribuídos entre os participantes. Além do conteúdo sobre IST, as cartas possuem, levando em consideração a taxonomia de Bloom, indicação do nível de dificuldade com determinadas habilidades nos domínios cognitivo e afetivo, uma vez que, no domínio psicomotor propriamente dito, estão envolvidas habilidades de desenvolvimento do jogo relacionadas a movimentos e padrões de articulação. Tudo isso permite ao aluno a possibilidade de auto avaliação e funciona como um instrumento metalinguístico, ou seja, aprender a aprender. Já no rodapé, a carta possui uma orientação de como proceder ao jogo em caso de acerto ou erro, quanto maior a complexidade, mais se anda para frente e menos se anda para trás no tabuleiro.

Para a execução do jogo, os alunos devem ser divididos em duplas, o ideal é que a cada tabuleiro forme-se uma equipe composta por duas ou três duplas, que serão rivais. Junto ao tabuleiro fica um outro aluno (árbitro) com as cartas o dado, o cronômetro e o 
manual de instruções. O início do jogo acontece com o lançamento do dado. Aquela dupla que tirar maior número indicado nele será a primeira a sortear uma carta no jogo e, seguindo a numeração no lançamento do dado, terá a definição da segunda dupla e assim por diante. No caso de saírem números iguais, o lançamento é repetido, até ser definida a ordem das duplas.

Quando cada dupla (somente um aluno por vez) escolher uma carta aleatoriamente na mão do árbitro, terá 60 segundos marcados em cronômetro (pelo árbitro) para apresentar uma resposta. Cada carta acessada é retirada do jogo. Se a dupla acertar dentro do tempo estipulado, percorre o número de casas previsto. Mas, no caso de perguntas em situação de dúvida, a dupla usufruirá outros 60 segundos para recorrer ao trabalho escrito e a anotações nos cadernos. A cada 30 segundos a mais do tempo concedido, eles andarão menos casas que o previsto (se forem três casas, passa para duas, uma, até zero). Nesse caso, terão até 120 segundos para andar pelo menos uma casa. Se errarem, voltam o número de casas que estiver indicado como penalidade na carta e esperam por sua vez para tirarem uma próxima (que sairá também aleatoriamente do bolo de cartas). A dupla seguinte pode tentar acertar a pergunta que ficou errada. Se acertar, anda a quantidade de casas indicada, e continua respondendo até errar. Daí passa a vez quando isso acontecer. Assim, só anda quem acerta. E quem acerta mais, percorre mais casas no tabuleiro. Não será permitido consultas a mídias nem a qualquer outro integrante externo à dupla. Caso isso aconteça, deverá retornar ao ponto de partida no tabuleiro, e no caso de reincidência, ocorrerá a desclassificação. Ganha a dupla que chegar primeiro ao final do tabuleiro. É importante destacar que, a fim de atender uma turma em números aproximados de alunos como a deste trabalho, faz-se necessária a utilização de vários tabuleiros simultâneos. 
Figura 8-Tabuleiro.

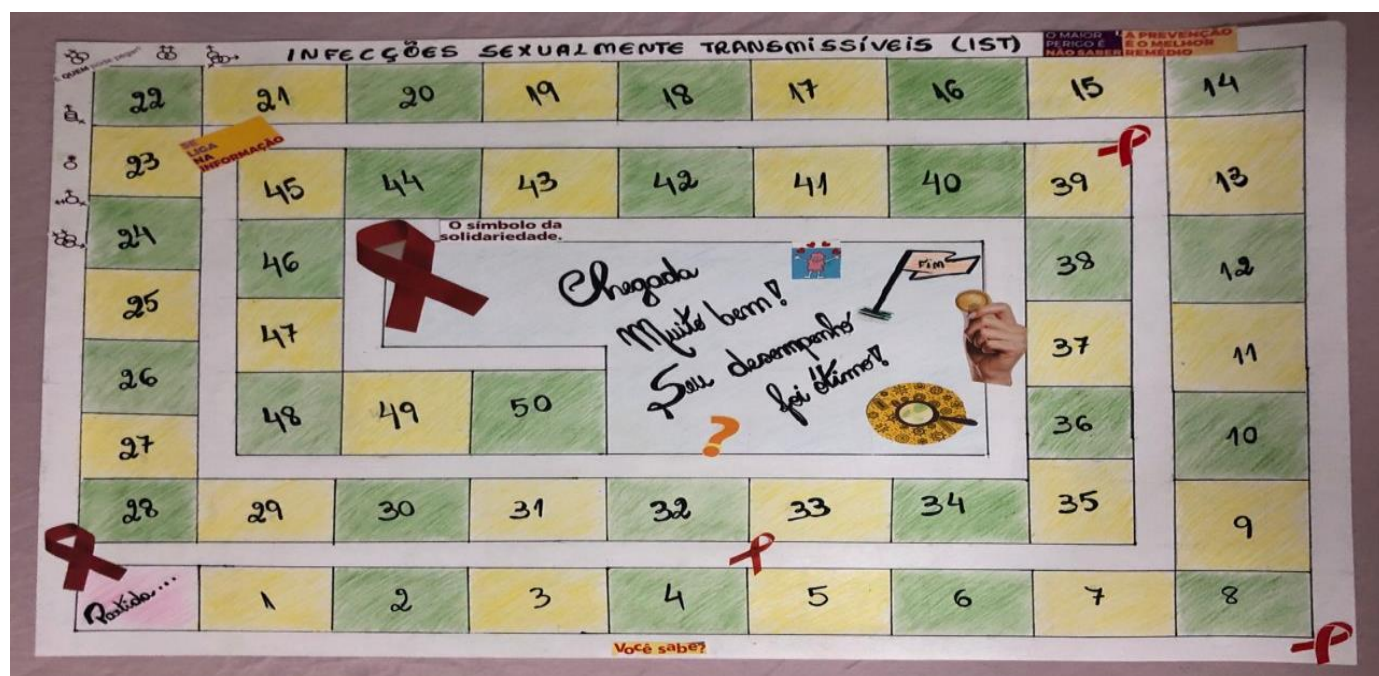

Fonte: Fornecido pelos alunos e autora (2021).

Figura 9 - Exemplos das cartas.

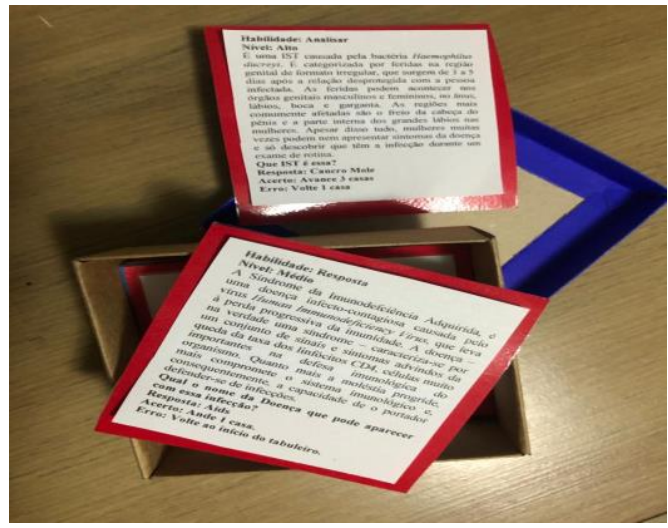

Fonte: Fornecido pelos alunos e autora (2021).

Figura 10 - Pinos e dado.

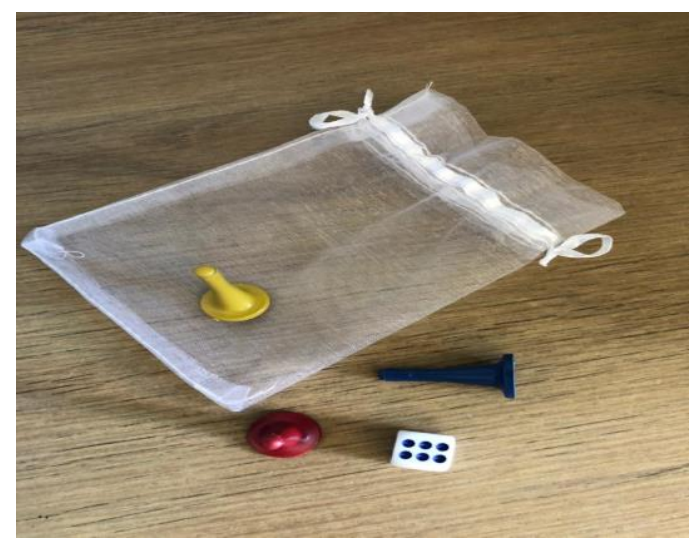

Fonte: Fornecido pelos alunos e autora (2021). 


\section{DISCUSSÃO}

Passaremos agora a apresentar e discutir o comportamento discente observado na turma que integrou este relato. A discussão baseia-se na experiência e tem como referências as ações e falas que denotem engajamento ou desengajamento à proposta de tarefa de aprendizagem. Ademais, incluímos na discussão as atitudes da professora/observadora que em todo o processo buscou despertar o interesse dos alunos para promover o engajamento. Nesse sentido, o interesse é um construto associado com o nível de atenção do estudante, enquanto a motivação é um construto relacionado com a superação das barreiras para que haja engajamento (MORAES; VARELA, 2007). Ambos, interesse e engajamento, são fundamentais para o sucesso de uma metodologia ativa potencialmente significativa, centrada no aluno.

O interesse é central para a aprendizagem significativa, isto é, o aprendiz deve estar predisposto a aprender significativamente e, para isso, deve direcionar a atenção para os novos conhecimentos a partir do saber prévio (AUSUBEL, 2003). O interesse está relacionado com a determinação e persistência em processar determinado tipo de informação preferencial em relação às tantas outras disponíveis (HIDI, 2006). É um construto não apenas associado com a atenção, mas também com o afeto. $O$ afeto está relacionado com as funções mentais responsivas aos efeitos causados pelas experiências durante a vida de cada indivíduo, dirigindo o comportamento de aproximação ou afastamento ao estímulo externo (EKKEKAKIS, 2013). Os efeitos gerais do afeto positivo de aproximação (i.e. em relação ao objeto externo) são: a) elevar os níveis de proatividade e diminuir procrastinação, b) direcionar o indivíduo para o objeto, c) iniciar uma atividade e permanecer ativo, d) afetar a capacidade cognitiva para o aprendizado e para a elaboração de estratégias (BIDDLE; MUTRIE, 2008).

Ao analisar as propostas, percebe-se que em totalidade existiu uma atmosfera de ludicidade, momentos de ensino trabalhados de uma forma envolvente, extrovertida e descontraída que fomentou sentimentos de interação e tornou o processo prazeroso. 0 resultado final de todos os trabalhos apresentados pelos grupos, indistintamente, faz perceber o engajamento das equipes e o elevado grau de criatividade nas produções. Para além do engajamento dos educandos, outros princípios para uma boa prática educacional fazem-se presentes na unidade didática como a cooperação, a interação, a diversidade e a 
responsabilidade dos educandos com relação ao trabalho dos pares (CHICKERING; GAMSON, 1987).

Destaca-se a observação de uma aluna que relatou uma estratégia de memorização do conteúdo que ela criou para o jogo de sua equipe (tabuleiro), dizendo que identificou que as infecções causadas por vírus começavam sempre com a letra " $\mathrm{H}$ " (herpes, hepatite, HIV, HPV). Esse relato evidencia uma técnica de relembrança, que consiste em trazer à consciência uma informação previamente aprendida (SMITH; ROEDIGER; KARPICKE, 2013). Uma atitude como a dessa aluna torna claro o valor da atividade proposta no sentido de produzir autonomia, incentivar o autodidatismo e aguçar a criatividade e a elaboração de estratégias pessoais de aprendizado, atributos estes reconhecidos nas metodologias ativas que visam delegar maior protagonismo ao estudante durante o processo de aprendizagem.

Percebe-se um forte ponto positivo neste trabalho que foi o envolvimento dos discentes em diversas manifestações de sentimentos e emoções, engajamento na pesquisa e elaboração de respostas com as propostas apresentadas. Nestas, por sua vez, não é de se surpreender que metade delas tenha se concentrado em jogos, pois a utilização deles no cenário da educação contemporânea contempla mais do que entretenimento e a assimilação das características naturais que se propõe, atua como alavanca das práticas educativas, nas quais o aluno, ao se deparar com um "erro", encara-o como um desafio, e este se torna um momento significativo de aprendizagem. Aliás, a elaboração de um jogo pelos próprios alunos configura um processo metalinguístico no escopo das metodologias ativas, pois o ensino por meios de jogos está entre as muitas possibilidades da aprendizagem ativa (LIMA, 2017).

É sabido que um novo paradigma para o processo ensino-aprendizagem precisa ser exibido na educação contemporânea, e essa urgência traz a reflexão de nossas alternativas de ensino. O cenário atual de sociedade em que vivemos remonta a necessidade de indivíduos reflexivos e agindo com criticidade. A fim de que essas competências sejam alcançadas no meio escolar, o ensino precisa articular conteúdos com aplicabilidade. De tal forma que seja possível o desenvolvimento de habilidades nos estudantes para que as competências sejam atingidas. No âmbito das políticas educacionais, a unidade didática apresentada neste trabalho nos parece adequada para o desenvolvimento da habilidade "EM13CNT207" da Base Nacional Comum Curricular (BNCC) que propõe: 
Identificar, analisar e discutir as vulnerabilidades vinculadas aos desafios contemporâneos aos quais as juventudes estão expostas, considerando as dimensões física, psicoemocional e social, a fim de desenvolver e divulgar ações de prevenção e de promoção da saúde e do bem-estar. (BRASIL, 2000b, p. 557).

O desenvolvimento desta e outras habilidades tornam-se viável através de uma nova abordagem na configuração do ensino. Metodologias ativas são processos interativos no campo do conhecimento, que permite alto grau de protagonismo dos alunos, no qual o professor exerce o papel de mediador ou orientador para que o estudante faça pesquisa, reflita e decida de forma autônoma. Isso implica estímulo da educação continuada, partindo do conhecimento prévio, com foco em despertar o interesse e promover o engajamento do aprendiz.

\section{CONCLUSÃO}

Desde o momento inicial da proposta do trabalho aos alunos, ficou evidente uma manifestação proativa de interesse dos mesmos ao abordar o tema. O assunto, por estar intimamente ligado à sexualidade e despertar o interesse dos jovens a transitar no campo das emoções e em turbilhões de dúvidas, permitiu um momento de contexto lúdico, com metodologia ativa. Foi-lhes permitido, além da liberdade da criação de uma resposta frente a um desafio, uma verdadeira autonomia na elaboração da proposta de sua equipe, desde a ideia até sua aplicação.

Em síntese, concluímos que o produto deste trabalho, caracterizado por uma unidade didática, desafiou os alunos a buscarem soluções e produtos particulares e colocouos na posição de protagonistas do processo ensino-aprendizagem. Vale ressaltar que, configurado por relato pessoal, este trabalho não tem a pretensão de seus resultados serem reprodutíveis, embora o oferecimento de um produto educativo permita a possibilidade de utilização do mesmo em outros contextos e diferentes realidades. O planejamento didático em si não gera motivação intrínseca no aluno de forma imediata, desse modo, é de fundamental importância uma exposição incisiva do professor para despertar o interesse e o engajamento produtivo. 


\section{REFERÊNCIAS}

AUSUBEL, P. D. Aquisição e retenção de conhecimentos: uma perspectiva cognitiva. Lisboa: Plátano Edições Técnicas, 2003.

BIDDLE, J. H.; MUTRIE, N. Psychology of physical activity: determinants, well-being and interventions. 2. ed. London, NY: Taylor and Francis Group, 2008.

BORBA, J. B. Uma breve retrospectiva do ensino de Biologia no Brasil. 2013. Dissertação (Especialização em Educação Métodos e Técnicas de Ensino. Modalidade Ensino a Distância) - Universidade Tecnológica Federal do Paraná, Medianeira, 2013. Disponível em: http://repositorio.roca.utfpr.edu.br/jspui/bitstream/1/4689/1/MD_EDUMTE_I_2012_12.pdf . Acesso em: 04 fev. 2021

BRÁS, M. A. M. A sexualidade do adolescente: a perspectiva do profissional de enfermagem dos cuidados de saúde primários. 2008. 689 f. Tese (Doutorado em Ciências da Enfermagem) - Instituto de Ciências Biomédicas Abel Salazar, Universidade do Porto, Porto, 2008.

BRASIL. Ministério da Educação. Base Nacional Comum Curricular. Brasília, DF: MEC, 2000b. Disponível em: http://basenacionalcomum.mec.gov.br/\#/site/inicio. Acesso em: 7 fev. 2021.

BRASIL. Ministério da Educação. Parâmetros curriculares nacionais. Brasília, DF: MEC, 2000a. Disponível em: http://portal.mec.gov.br/setec/arquivos/pdf/BasesLegais.pdf. Acesso em: 04 fev. 2021.

BRASIL. Ministério da Saúde. Proteger e cuidar da saúde dos adolescentes na atenção básica. Brasília, DF: Ministério da Saúde, 2018. Disponível em http://bvsms.saude.gov.br/bvs/publicacoes/proteger_cuidar_adolescentes_atencao_basica_ 2ed.pdf. Acesso em: 23 mar. 2020.

BRASIL. Ministério da Saúde. Secretaria de Vigilância em Saúde. Boletim Epidemiológico HIV/AIDS, v. 10, n. 1, p. 3-60, 2017. Disponível em: http://www.aids.gov.br/ptbr/pub/2017/boletim-79 epidemiologico-hivaids-2017. Acesso em: 05 mar. 2020.

CHICKERING, A. W.; GAMSON, Z. F. Seven principles for good practice in undergraduate education. AAHE Bull., [S. I.], v. 39, n. 7, p. 1-7, 1987. Disponível em: https://www.lonestar. edu/multimedia/sevenprinciples.pdf. Acesso em: 4 fev. 2021.

CIRIACO, N. L. C. et al. A importância do conhecimento sobre Infecções Sexualmente Transmissíveis (IST) pelos adolescentes de uma abordagem que vá além das concepções biológicas. Revista Em Extensão, Uberlândia, v. 18, n. 1, p. 63-80, 2019.

EISENSTEIN, E. Adolescência: definições, conceitos e critérios. Adolescência \& Saúde, [S. I.], v. 2, n. 2, p. 6-7, 2005. Disponível em:

http://www.adolescenciaesaude.com/detalhe_artigo.asp?id=167. Acesso em: 04 fev. 2021. 
EKKEKAKIS, P. The measurement of affect, mood, and emotion: a guide for health-

behavioral research. New York, NY: Cambridge University Press, 2013.

GOMES, W. A. et al. Nível de informação sobre adolescência, puberdade e sexualidade entre adolescentes. Jornal de Pediatria, Rio de Janeiro, v. 78, n. 4, p. 301-308, 2002.

HIDI, S. Interest: a unique motivational variable. Educational Research Review, [S. I.], v. 1, n. 2, p. 69-82, 2006.

$\mathrm{HOHL}, \mathrm{R}$. et al. Aprendizagem, memória e criatividade: estratégias cognitivas aplicadas durante a Semana do Cérebro 2019. Aprendizagem Significativa em Revista, [S. I.], v. 9, n. 3, p. 27-49, 2019. Disponível em:

http://www.if.ufrgs.br/asr/artigos/Artigo_ID160/v9_n3_a2019.pdf. Acesso em: 4 fev. 2021.

LIMA, V. V. Constructivist spiral: an active learning methodology. Interface (Botucatu), Botucatu, v. 21, n. 61, p. 421-34, 2017. Disponível em:

https://www.scielo.br/scielo.php?pid=S1414-

32832016005023103\&script=sci_arttext\&tlng=en. Acesso em: 4 fev. 2021.

MENEZES, E. T. Verbete educação informal. Dicionário Interativo da Educação Brasileira EducaBrasil. São Paulo: Midiamix Editora, 2001. Disponível em https://www.educabrasil.com.br/educacao-informal/. Acesso em: 3 fev. 2021.

MITRE, S. M. et al. Metodologias ativas de ensino-aprendizagem na formação profissional em saúde: debates atuais. Ciência \& Saúde Coletiva, Rio de Janeiro, v. 13, supl. 2, p. 21332144, 2008. Disponível em: https://www.scielo.br/scielo.php?script=sci_arttext\&pid=S1413$81232008000900018 \&$ lng=pt\&tlng=pt. Acesso em: 4 fev. 2021.

MORAES, C. R.; VARELA, S. Motivação do aluno durante o processo de ensino aprendizagem. Revista Eletrônica de Educação, [S. I.], ano 1, v. 1, n. 1, p. 1-15, 2007. Disponível em: https://web.unifil.br/docs/revista_eletronica/educacao/Artigo_06.pdf. Acesso em: 4 fev. 2021.

MOREIRA, M. A. Aprendizagem significativa: a teoria e textos complementares. São Paulo: Livraria da Física, 2012.

MOREIRA, M. A.; MASINI, E. F. S. Aprendizagem significativa: a teoria de David Ausubel. 2. ed. São Paulo: Centauro, 2012.

OLIVEIRA, D. C. et al. Conhecimentos e práticas de adolescentes acerca das DST/HIV/AIDS em duas escolas públicas municipais do Rio de Janeiro, Esc Anna Nery Rev Enferm, [S. I.], v. 13, n. 4, p. 833-841, 2009. Disponível em: http://www.scielo.br/pdf/ean/v13n4/v13n4a20.pdf. Acesso em: 22 fev. 2020.

NÚMERO de Infecções Sexualmente Transmissíveis (IST) aumenta. Febrasgo, São Paulo, 2018. Disponível em: https://www.febrasgo.org.br/pt/noticias/item/565-numero-deinfeccoes-sexualmente-transmissiveis-ist-aumenta. Acesso em: 4 abr. 2020. 
SMITH, M. A.; ROEDIGER, H. L.; KARPICKE, J. D. Covert retrieval practice benefits retention as much as overt retention practice. Journal of Experimental Psychology: learning, memory and cognition, [S. I.], v. 39, p. 1712-1725, 2013. Disponível em:

https://core.ac.uk/download/pdf/233204536.pdf. Acesso em: 4 fev. 2021.

WEINSTEIN, Y., MADAN, C. R., SUMERACKI, M. A. Teaching the science of learning. Cognitive research: Principles and Implications, [S. l.], v. 3, n. 2, p. 1-17, 2018.

ZABALA, A. A prática educativa: como ensinar. Porto Alegre: Artmed, 1998. 